\title{
O MERCADO DE TRABALHO FORMAL EM BERTIOGA SOB A ERSPECTIVA DE GÊNERO
}

\author{
EL MERCADO DE TRABAJO FORMAL EM BERTIOGA DE UNA PERSPECTIVA DE \\ GÉNERO
}

THE FORMAL LABOR MARKET INBERTIOGA FROM A GENDER PERSPECTIVE

\author{
Maíra DARIDO DA CUNHA ${ }^{1}$ \\ Guilherme dos Santos DIAS RODRIGUES ${ }^{2}$
}

RESUMO: O presente artigo faz uma análise acerca do mercado de trabalho formal no município de Bertioga - SP, relacionando as questões entre crescimento populacional, trabalho e gênero, com o recorte oferecido, ano a ano, desde a emancipação do município. A pesquisa se baseia na dialética em que se pratica com a historicidade sobre o capitalismo, e os arranjos neoliberais e por fim, com a inserção da mulher no mercado de trabalho do município de Bertioga - SP. Podemos analisar as contradições da reestruturação produtiva e levantar hipóteses consistentes: a crise estrutural do capitalismo interfere diretamente na divisão sexual do trabalho e; a mulher está inserida nos postos de trabalhos informais e precários.

PALAVRAS-CHAVE: Trabalho. Gênero. Empregos formais.

RESUMEN: Este artículo analiza el mercado laboral formal en el municipio de Bertioga $S P$, relacionando los problemas entre el crecimiento de la población, el trabajo y el género, con el recorte ofrecido, año tras año, desde la emancipación del municipio. La investigación se basa en la dialéctica en la que se practica con la historicidad sobre el capitalismo y los arreglos neoliberales y, finalmente, con la inserción de la mujer en el mercado laboral del municipio de Bertioga - SP. Podemos analizar las contradicciones de la reestructuración productiva y plantear hipótesis consistentes: la crisis estructural del capitalismo interfiere directamente con la división sexual del trabajo y; la mujer se inserta en trabajos informales y precarios.

PALABRAS CLAVE: Trabajo. Género. Empleos formales.

ABSTRACT: This article analyzes the formal labor market in the city of Bertioga - SP, relating the issues between population growth, work and gender, with the cut offered, year by year, since the emancipation of the municipality. The research is based on the dialectic in which it is practiced with the historicity about capitalism, and the neoliberal arrangements and finally, with the insertion of women in the labor market in the municipality of Bertioga SP. We can analyze the contradictions of productive restructuring and raise consistent

${ }^{1}$ Faculdade Bertioga (FABE), Bertioga - SP - Brasil. Docente da Faculdade. Doutora em Educação Escolar (UNESP). ORCID: https://orcid.org/0000-0002-8263-882X. E-mail: maira_darido@yahoo.com.br

${ }^{2}$ Universidade Federal de São Paulo (UNIFESP), Santos - SP - Brasil. Mestrando em Serviço Social e Políticas sociais. ORCID: https://orcid.org/0000-0003-0650-7518. E-mail: gdiasbert@ gmail.com 
hypotheses: the structural crisis of capitalism directly interferes with the sexual division of labor and; the woman is inserted in informal and precarious jobs.

KEYWORDS: Sociology of work. Genre. Formal jobs.

\section{Introdução}

A proposta deste artigo é a reflexão sobre a mulher e o trabalho, mais especificamente nos empregos formais, com o recorte no município de Bertioga - SP, o que mais cresce na Região Metropolitano da Baixada Santista, e apontado por vários anos como o que mais cresce, proporcionalmente, no estado de São Paulo - e analisado em gráficos por gênero.

Partindo da importância de estudar o lugar da mulher no mundo do trabalho, o presente artigo foi desenvolvido no curso de Tecnologia da Gestão Pública, na Universidade Virtual do estado de São Paulo, polo Bertioga. Dessa forma, foram levantados dados empíricos sobre o crescimento populacional, por gênero e população economicamente ativa, e em destaque, por gênero e empregos formais ano a ano, em um recorte dos últimos 15 anos.

$\mathrm{Na}$ primeira parte apresentaremos a conceituação de gênero, estreitando o entendimento sobre o papal da mulher na história, tanto na esfera produtiva como reprodutiva, buscando a reflexão da importância de suas lutas. Assim como, inserir a mulher como ser que busca através do trabalho, muitas vezes duplo, o reconhecimento de igualdade na sociedade.

Por conseguinte, na segunda parte, apresentaremos a historicidade que encadeou o capitalismo, desde o início da era industrial, passando por sistemas conceituados como taylorismo, fordismo e por fim, toyotismo. Nesse entremeio, dialogamos com as literaturas pertinentes que apresentam a função da mulher nesse sistema, e mais, de que forma está inserida nesse mercado de trabalho.

$\mathrm{Na}$ terceira parte, reservamos à apresentação do município de Bertioga, o seu crescimento populacional e os postos de trabalhos gerados, sempre recortando por gênero, e desde a sua emancipação político-administrativa. Para tanto, os dados da Fundação SEADE apresentados em gráficos evidenciam a importância do artigo.

$\mathrm{O}$ presente estudo dialoga com as principais literaturas sobre trabalho e gênero, e oferece uma breve reflexão, mais profunda, do cenário atual no município de Bertioga. A inserção da mulher do mercado de trabalho ganha estimada relevância quando estamos falando dos efeitos neoliberais causados nos postos de trabalho, como a informalidade e a precarização. 
As considerações apontam para uma faixa considerável de mulheres fora dos postos de trabalhos formais, e principalmente, levantam a hipótese de situações concomitantes, que a literatura disserta com embasamentos claros dentro da historicidade do capitalismo. Assim, a mulher se torna referência nesse estudo em razão dos dados consonantes no município que mais cresce populacionalmente, no maior estado do país, São Paulo.

\section{Luta por direitos e o papel social da mulher}

$\mathrm{Na}$ esteira da história, se o Iluminismo pregava que todos os "homens são iguais por natureza", a extrema separação entre as esferas públicas do governo e a privada da família e do lar na qual homens e mulheres tinham papéis sociais completamente distintos, fazia com que a chamada teoria da complementaridade sexual soar natural. Dizia-se que as mulheres não eram iguais aos homens, e sim, opostos complementares, teoria esta que se adaptou facilmente aos moldes da época e fez a desigualdade parecer algo inerente às relações entre homens e mulheres (SCHIENBINGER, 2001).

Logo, as mulheres não eram vista como somente inferiores a eles, mas incomparáveis, por diferenças fundamentais. Conforme aponta Scott (1995) as mulheres eram vistas como diferentes; física, moral e intelectualmente. Transplantando ao cenário social da época, as mulheres não tinham a oportunidade de frequentarem a escola, mercado de trabalho, ou participarem da esfera pública. Foi somente com o movimento das mulheres, a partir das décadas de 1870 e 1880 concessões foram feitas e se permitiu o ingresso do sexo feminino nas carreiras modernas, podendo participar também das universidades e, ainda que não bem vistas, inseridas em algumas carreiras no mercado de trabalho (SCAVONE, 2008).

Scott (1995) afirma que pesquisadoras feministas com um a visão política mais global apelavam regularmente às categorias de classe, raça e gênero para "a escrita de uma nova História". A utilização do termo "gênero" pelas feministas americanas objetivava enfatizar o caráter fundamentalmente social das distinções baseadas no sexo. A palavra indicava uma rejeição do determinismo biológico implícito no uso de termos como "sexo" ou "diferença sexual".

O termo "gênero" enfatizava igualmente o aspecto relacional das definições normativas da feminilidade. Passou-se, através desta visão, a descentrar a mulher, única e exclusivamente, como o foco de estudos, e a analisar homens e mulheres como definidos em termos recíprocos, não se podendo compreender qualquer um dos sexos de maneira separada (SCHIENBINGER, 2001). 
Mais recentemente, a situação de vida das mulheres, especificamente, as peculiaridades oriundas das diferenças de gênero, passou a ocupar algum espaço como tema de pesquisa e debate nos centros universitários. Os movimentos sociais de contestação das décadas de 1969 e 1970 marcados pela presença feminina maciça tais como as manifestações estudantis, o movimento operário e as lutas políticas e sociais, podem ser considerados os desencadeadores das discussões centradas na mulher, que deixa de ser focalizado apenas como "estudo de minorias" ou "grupo desviante", passando a ser analisada como agente social e histórico e como sujeito dos estudos.

Com o advento da modernização e industrialização crescente, em especial a partir dos anos 1960, nota-se profundas transformações sociais, políticas, econômicas e culturais que modificam toda a estrutura da sociedade. A começar pela noção de família. A inserção da mulher no mercado de trabalho transformou os pilares da instituição família no sentindo em que esta teve que se adaptarem as necessidades da vida contemporânea e da nova da adequação do papel da mulher (BAUMAN, 2010).

Segundo Londa Shienbinger, podemos ver que a estruturação das instituições científica e o contexto histórico em que elas estão inseridas podem encorajar ou desencorajar a participação das mulheres nesse novo contexto do mercado de trabalho. No entanto, pela divisão de trabalho moderna às mulheres têm que geralmente optar ou pela carreira profissional, ou pela manutenção da dita família tradicional. Via de regra, não podem optar por dedicação exclusiva a uma e outra esfera e são obrigadas a uma dupla jornada de trabalho. São provedoras e responsáveis pelo funcionamento do lar.

\section{A inserção da mulher no mercado do trabalho}

O fordismo e o taylorismo, como princípios de organização, permeiam a conjuntura da indústria capitalista. Assim, a indústria passa a ser a principal forma de manifestação da produção capitalista. Esse inicia, entre o final do século XIX e início do século XX, a inserção dos trabalhadoreslas em sistemas conceituados, padronizados, e que se alastrou por todo o mundo, como modelo (NOGUEIRA, 2004, p. 27-29).

O taylorismo se desenvolve dentro do conceito de separação das atividades, base e produção, em que os operários executam atividades separadas para a entrega de um produto (BIHR, 1998, p.39). O fordismo se caracteriza por uma forma de produção e gerenciamento, em que funcionários especializados produziam praticamente todo o produto, através de uma hierarquização (GOUNET, 1999, p. 18). 
Antunes (1999) ressalta que, esse binômio contribuiu para o aumento do operáriomassa, da produção homogênea e de grande quantidade. Ainda, expõe a fragmentação do trabalho, em que estabelece fortemente a hierarquização. Menicucci (1999) e Nogueira (2004), apontam que nesse entremeio, o trabalhador muitas vezes não sabe o porquê está executando determinada tarefa, e assim sem conhecimento do processo do trabalho.

Por conseguinte, o toyotismo, que se tornou uma nova organização do trabalho: buscava produzir com alta tecnologia com menos recursos; chamada de produção enxuta, o toyotismo supera o fordismo, que já tinha incorporado às práticas de Taylor, e; atende à crise de produção, em que a questão econômica se torna fundamental para continuar com a produção em ascensão, assim denominamos como uma nova reestruturação produtiva (NOGUEIRA, 2004; GOUNET, 1999).

Essa crise apontada no fordismo foi amplamente debatida por Harvey (1992) e Bihr (1998), a "acumulação flexível" apresenta a busca pelo capital para contornar a crise de produção, e o toyotismo representava novos investimentos em busca da produção enxuta, certo de se combater a diminuição dos ganhos, o trabalho improdutivo, o não consumo e etc. Foram alguns fatores que estabeleceram o enfraquecimento do fordismo e taylorismo.

[...] Caracteriza-se pelo surgimento de setores de produção inteiramente novos, novas maneiras de fornecimento de serviços financeiros, novos mercados e, sobretudo, taxas altamente intensificadas de inovação comercial, tecnológica e organizacional. A acumulação flexível envolve rápidas mudanças dos padrões do desenvolvimento desigual, tanto entre setores como entre regiões geográficas, criando, por exemplo, um vasto movimento no emprego no chamado "setor de serviços" (HARVEY, 1992, p. 140).

Ora, se há uma reestruturação produtiva, oriunda da crise estrutural do capital em que busca a "produção enxuta", logo a força de trabalho tem que se adaptar a essa nova onda. E Antunes (1999) salienta, que adicionada a lutas de classes $^{3}$, para esse estancamento econômico, faz com que haja a necessidade da reestruturação do próprio capital. Esse movimento é o neoliberalismo. O neoliberalismo busca, por exemplo, a privatização das empresas públicas, o afastamento do Estado do setor produtivo, as flexibilizações das leis, medidas que buscam desregulamentar o Estado, entre outras.

Os anos 70 foram fundamentais para esse processo de transição. Também, claramente entre os anos 80 e 90 ocorre o avanço do neoliberalismo. O neoliberalismo disfarçado de

3 Ocorridas ao final dos anos 60 e 70 solapavam pela base o domínio do capital e afloravam as possibilidades de uma hegemonia (ou uma contra hegemonia) oriunda do mundo do trabalho (ANTUNES, 1999, p. 42). 
modernização e gestão técnica inovadora em busca da flexibilização (MARY CASTRO, 2001, p. 275).

Concomitantemente, os anos 70 estão passando pelo processo de luta das mulheres, em que se busca a emancipação da mulher, e para isso elas ocupam os movimentos de lutas de classes e os debates sobre o papel da mulher. Nogueira reforça que, "a mulher estava predestinada ao papel de mãe e esposa, tendo a responsabilidade de cultuar o conceito de família como instituição básica e universal" (NOGUEIRA, 2004, p. 37).

É nessa década que o combate à opressão contra a mulher torna-se mais acentuado: era preciso, mais do que nunca, lutar pela sua emancipação econômica e social, pelo seu direito ao trabalho, com todas as especificidades que isso implica, como, por exemplo, salários iguais para trabalhadores iguais, além da reivindicação de uma divisão mais junta no trabalho doméstico, na esfera reprodutiva, libertando, ao menos parcialmente, a mulher da dupla jornada (NOGUEIRA, 2004, p. 37).

O avanço do neoliberalismo, devido à crise estrutural do capital, invariavelmente resulta na precarização e na informalidade do trabalho (ANTUNES, 1999). Tal movimento ocorre e diz respeito às mulheres, apesar de estar inseridas no espaço formal e informal, mas reservam-se os empregos precários e vulneráveis; em contra partida, os homens assalariados das indústrias tem em seus proventos a forma de "colaborar" com a reorganização produtiva, aceitando a redução ou estagnação salarial (HIRATA; LE DOARÉ, 1999, p. 10).

Portanto, esses ajustes neoliberais, até os dias de hoje em diversos espaços, preteriram a mulher, "levando a uma precarização ainda maior para o conjunto da classe trabalhadora, incluindo o contingente masculino" (HIRATA, 2001; 2002). Esses efeitos resultantes do neoliberalismo ${ }^{4}$ ressaltam que outras variáveis determinantes, desde o movimento iniciado nos anos 70 pelas mulheres, aqui citado, ainda continuam sem o tratamento necessário, como afirma Nogueira no diálogo com os textos de Hirata:

[...] as desigualdades de salários não diminuíram, que as condições de trabalho e de saúde não melhoraram, e que a divisão do trabalho doméstico não se modificou substancialmente, a despeito de um maior envolvimento nas responsabilidades profissionais por parte das mulheres. Tudo indica que, apesar do aumento do número de empregos, as desigualdades sociais que o capitalismo em escala global, através de sua política de flexibilização, trouxe para as relações de trabalho e para a saúde dos trabalhadores pioraram muito (NOGUEIRA, 2004, p. 39).

4 Helena Hirata conclui essa síntese em um estudo que aponta esses efeitos na Ásia, Europa e América Latina. 
Dada a contextualização da luta por direitos iguais e busca por inserção de forma equânime ao mercado de trabalho pelas mulheres, é possível transplantar a discussão para o papel da mulher no mercado de trabalho no município de Bertioga - SP.

Dessa forma, a pesquisa investiga as especificidades do município de Bertioga - SP, buscando elementos que analisem o crescimento populacional desproporcional do município (SEADE, 2018), apontada por alguns anos seguidos como o município que mais cresce no estado de São Paulo (IBGE, 2017) relacionando este dado com as taxas de emprego formal no município, podendo estabelecer um cenário do papel da mulher no mercado de trabalho. Estão elas na formalidade ou informalidade?

\section{Bertioga e os empregos formais por gênero}

O município de Bertioga, segundo dados do IBGE (CENSO, 2010), tem 47.645 habitantes, e hoje, estimados em 61.736 habitantes (idem, 2018). Bertioga, pertencente à região da Baixada Santista, e entre os anos de 2010 e 2015, é a cidade que mais cresceu em todo Estado de São Paulo (SEADE, 2015).

Abaixo apresentamos um gráfico sobre esse crescimento populacional ${ }^{5}$ no município de Bertioga, em que o objetivo é apenas apontar graficamente como há aumento populacional ininterrupto desde a sua emancipação, em 1991, SEADE (2018):

Figura 1 - Gráfico: crescimento populacional no município de Bertioga

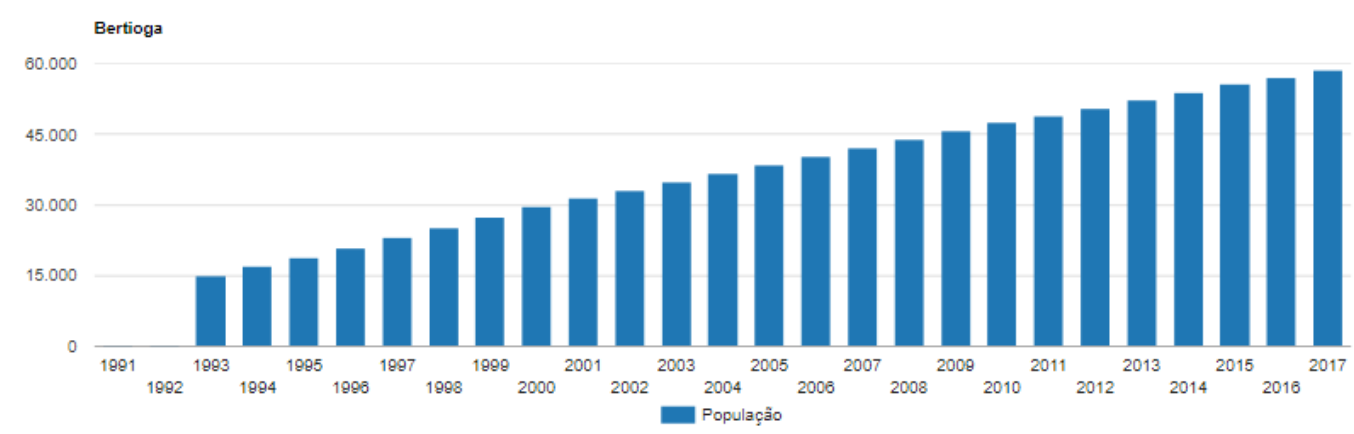

Fonte: Fundação SEADE (2018)

5 “As populações aqui apresentadas resultam de projeções elaboradas pelo método dos componentes demográficos. Este método considera as tendências de fecundidade, mortalidade e migração, a partir das estatísticas vitais processadas na Fundação Seade, e a formulação de hipóteses de comportamento futuro para estes componentes. A população de base, por idade e sexo, considera os resultados correspondentes aos diversos Censos Demográficos realizados pelo IBGE. As populações projetadas referem-se à $1^{\circ}$ de julho de cada ano" (SEADE, 2018). 
O aumento populacional entre $1993^{6}, 14.947$ habitantes, a $2017,58.595$ habitantes, se deu pela especulação imobiliária e pelo investimento em infraestrutura, originado principalmente pela construção das rodovias que interligavam a região com o município, e pela construção do empreendimento Riviera de São Lourenço (MAZZOLENIS, 2013).

Também, apresento no próximo gráfico o mesmo dado populacional, mas por gênero ${ }^{7}$, e a partir desse momento começamos a dialogar com o recorte do presente artigo, as mulheres nos empregos formais no município de Bertioga.

Figura 2 - Gráfico: dado populacional por gênero

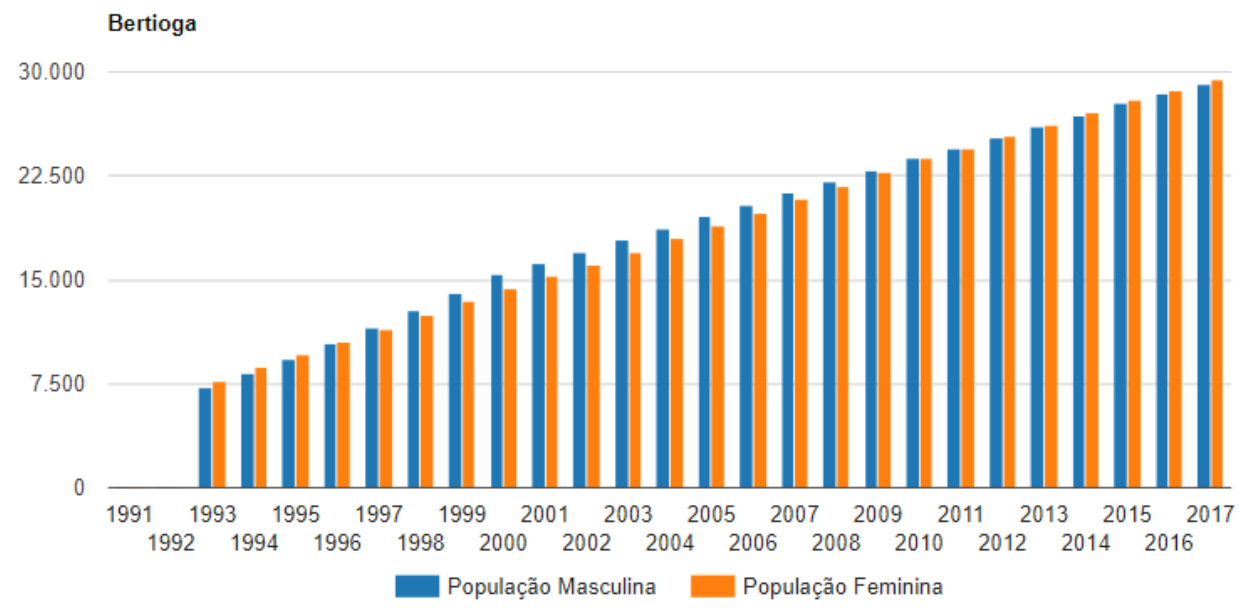

Fonte: Fundação SEADE (2018)

O gráfico acima apresenta que progressivamente a população feminina foi se aproximando da população masculina, e a partir de 2011 - a população feminina com 24.508 habitantes, e população masculina com 24.491 - a população feminina passou ser maior que a masculina.

Vamos analisar de que forma houve esse aumento populacional, considerando a faixa etária de 10 a $65 \operatorname{anos}^{8}$, faixa etária em que recortamos apenas para exemplificar o crescimento populacional estimado, e desmistificar que esse aumento pode ter ocorrido por natalidade, ou pelo aumento de habitantes na terceira idade advindos de outros municípios.

Uma das hipóteses é que com o processo de urbanização e industrialização marcado, principalmente a partir da década de 1980, nota-se uma nova configuração do padrão

6 Os dados de 1991 a 1992 não estão presentes porque o município ainda não era coberto pela Fundação SEADE, a partir de 1993 passa-se a cobrir o município de Bertioga, e em 1997 passa a cobrir os 645 municípios do estado de São Paulo (SEADE, 2018).

7 A metodologia se repete, apenas há uma separação por gênero (SEADE, 2018).

8 População Economicamente Ativa (PEA) - segundo o IBGE (2018), a PEA é composta pelas pessoas de 10 a 65 anos de idade que foram classificadas como ocupadas ou desocupadas. 
migratório do Brasil, sendo possível observar a diminuição dos fluxos migratórios interregionais e o consequente aumento das migrações de curta distância (RIBEIRO et al, 2015).

Mais especificamente, na Região Metropolitana da Baixada Santista - RMBS o estudo da mobilidade ganha importância devido aos recentes processos de transformações urbanas e demográficas que a região vem sofrendo. De um lado, dados censitários demonstram uma redução de crescimento populacional nos municípios considerados centrais, sendo que a população de Santos, cidade-polo, permanece praticamente a mesma desde a década de 1980 . Por outro lado, observou-se um forte crescimento populacional nas áreas periféricas da região, sendo a que mais cresce populacionalmente é o município de Bertioga - SP.

O padrão de crescimento percebido também pode estar relacionado com a migração intrametropolitana na RMSB, com um saldo migratório negativo do município de Santos e deslocamento populacional da cidade-polo em direção à periferia metropolitana, onde o custo da terra e para manutenção da vida são mais baratos (VAZQUEZ, 2011). Sendo assim, os movimentos pendulares relacionam-se com a expansão do espaço urbano, e, consequentemente, geram novas dinâmicas no território e na integração entre os municípios da região.

O aumento da população economicamente ativa indica que o município de Bertioga SP, alimentado por recentes empreendimentos imobiliários, se configura como um espaço de "oportunidades de emprego", seja na construção civil ou em serviços domésticos para as residências de temporada.

Figura 4 - População PEA (IBGE)

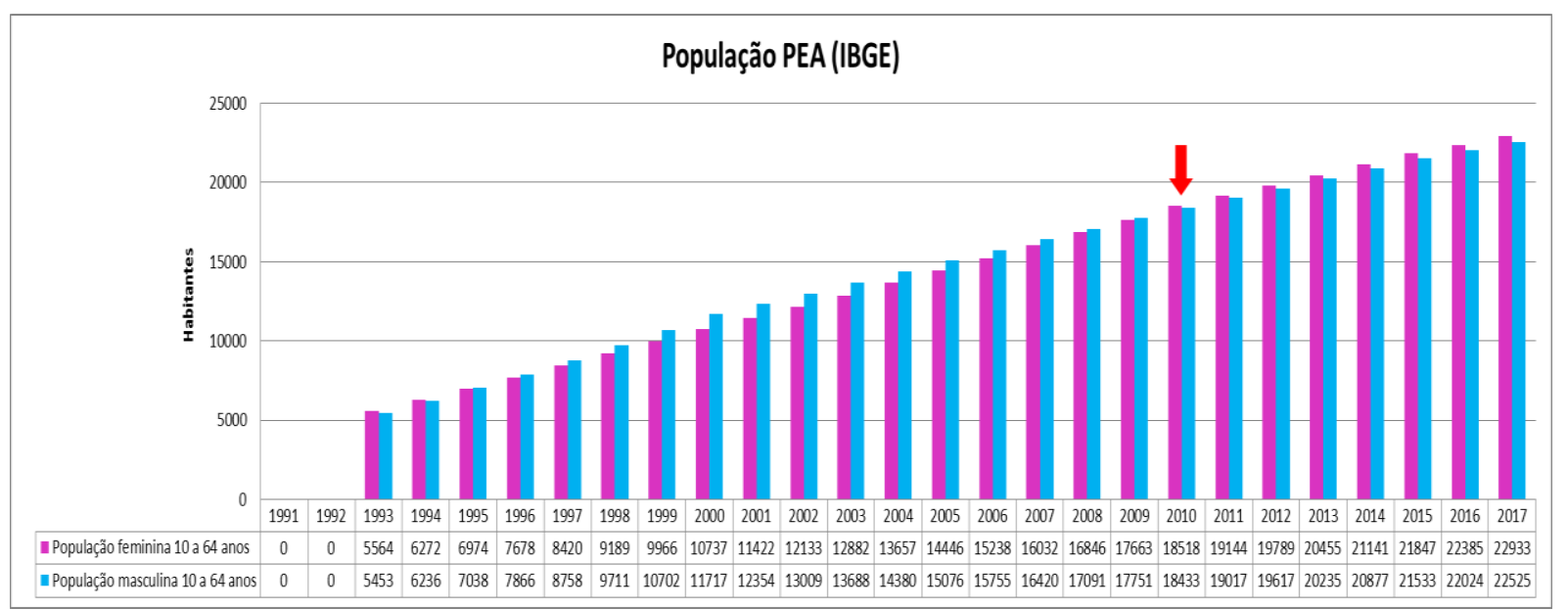

Fonte: Fundação SEADE (2018)

Podemos observar graficamente que em 2010 a população feminina passou a ser maior que a masculina - população feminina, 18.518 habitantes economicamente ativas, e 
população masculina, 18.433 habitantes economicamente ativos, logo conseguimos compreender que a população feminina tem papel determinante no crescimento da população economicamente ativa, ates mesmo do crescimento populacional total.

Portanto, apresentamos o gráfico populacional desde a emancipação do município de Bertioga, e em seguida separamos por gênero. Identificamos que em 2011, a população feminina ultrapassa a masculina, o que torna o debate relevante, pois até o ano de 2017 o cenário se repete. Para validar a sequência de nosso artigo, estratificamos por gênero e PEA, o que nos mostra que a população feminina está numericamente à frente antes, desde 2010.

O gráfico abaixo apresenta a quantidade de empregos formais ${ }^{9}$ ano a ano, por gênero. O ano de 2017 ainda não está disponibilizado pela Fundação SEADE.

Figura 5 - Gráfico: quantidade de empregos formais por gênero

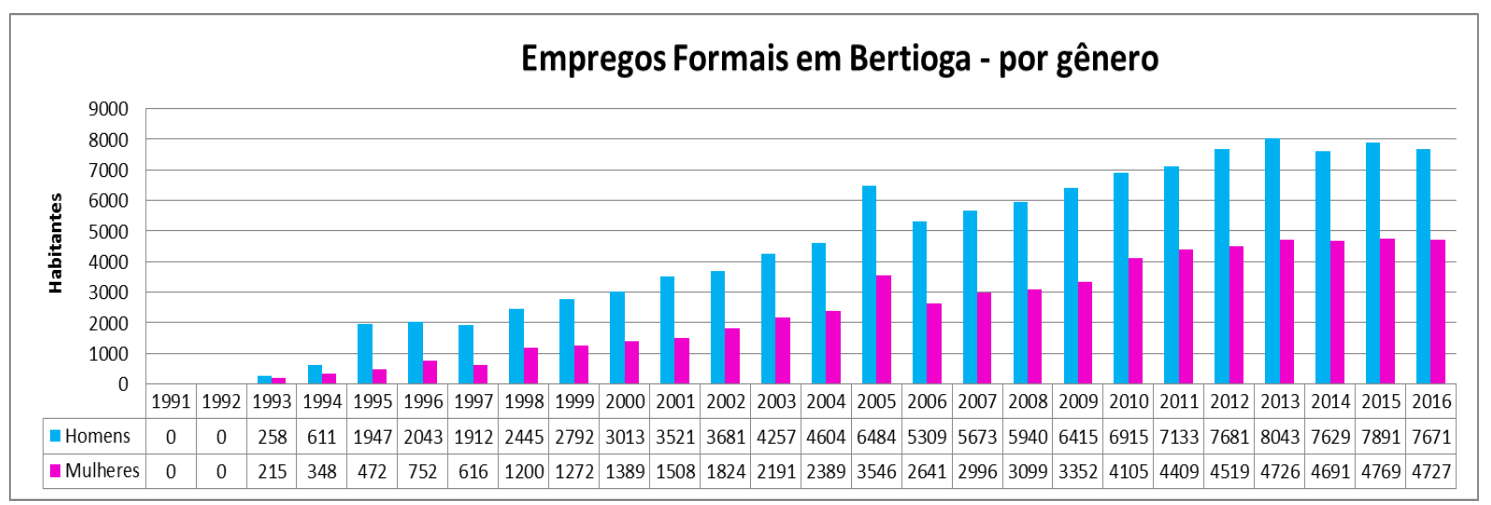

Fonte: Fundação SEADE (2018)

Podemos analisar no gráfico acima, que desde 2010, há uma manutenção dos empregos formais nos dois gêneros. Podemos observar que os postos de trabalhos são predominantemente masculinos. Não há a intenção neste artigo de apontar a flutuação de empregos por setor, nem mesmo, apontar o motivo da manutenção dos empregos. Fica evidente que nos dois gêneros há uma manutenção dos postos de trabalhos desde 2011.

9 O número de empregos formais corresponde aos vínculos empregatícios ativos em 31 de dezembro de cada ano ocupados por pessoas do sexo masculino, de acordo com informações fornecidas pelos contratantes quando da elaboração da Relação Anual de Informações Sociais - Rais, do Ministério do Trabalho e Emprego - MTE. Entende-se como vínculo empregatício a relação de emprego mantida com o empregador durante o ano-base e que se estabelece sempre que ocorrer trabalho remunerado com submissão hierárquica ao empregador e horário preestabelecido por este. Esta relação pode ser regida pela Consolidação das Leis do Trabalho - CLT ou pelo Regime Jurídico Único, no caso de empregado estatutário do serviço público. Adicionalmente, a Rais levanta dados sobre vínculos de trabalhador avulso, trabalhador temporário (Lei nº 6.019, de 3 de janeiro de 1974), menor aprendiz, diretor sem vínculo que tenha optado por recolhimento do FGTS e trabalhador com contrato de trabalho por prazo determinado (Lei n ${ }^{\circ}$ 9.601, de 21 de janeiro de 1998) (Anuário Estatístico Rais - Orientações para uso, 2010). As informações são fornecidas para cada um dos estabelecimentos empregadores, definidos "como sendo uma unidade que tenha um código específico no Cadastro Nacional de Pessoas Jurídicas - CNPJ ou no Cadastro Específico do INSS - CEI. Mesmo empresas que declaram a Rais de forma centralizada devem fornecer informações separadas para cada estabelecimento" (Anuário Estatístico Rais - Orientações para uso, 2010) (Ministério do Trabalho e Emprego - MTE. Relação Anual de Informações Sociais - Rais). 
A intencionalidade deste estudo é apontar o crescimento populacional, que predominantemente se apresenta maior no gênero feminino, porém, a manutenção desses postos de trabalho indaga às circunstâncias que essa população está inserida no mercado de trabalho, e mais especificamente a mulher.

\section{Considerações finais}

Nesse artigo procuramos mostrar como a mulher está inserida no mercado de trabalho, nos postos formais, e mais que isso, suscitar a discussão da divisão sexual do trabalho. A historicidade apresentada pede que entendamos pelo menos de forma inicial, as relações sociais de gênero como desiguais. Apesar de inseridas no mercado de trabalho formal, a mulher, no município de Bertioga, sempre está em menor número. Logo, essa participação da mulher no mercado de trabalho, dentro da esfera capitalista, está acompanhada com traços de informalidade (NOGUEIRA, 2004).

Isso se evidencia quando apresentamos o crescimento populacional por população economicamente ativa dividida por gênero, a mulher está em maior número, porém os postos de trabalhos formais continuam em manutenção, sem crescimento. A mulher sempre foi utilizada pelo capitalismo para exercer papéis com baixa remuneração, geralmente em empregos precários e informais, desde o advento da revolução industrial (SAFFIOTI, 1976).

Hirata (1999) ressalta, a inserção do trabalho feminino está veiculada com a flexibilização, certo de que se pressupõe a conciliação com as atividades do lar. E assim mesmo, a remuneração feminina tange a sensação de complementaridade. O presente estudo não traz um olhar positivo sobre a participação feminina no mercado de trabalho bertioguense, porque os fatores argumentados acima se fazem compreender.

As lutas por melhores condições estão em compreender que a emancipação feminina é a busca por direitos iguais, e assim, por direito de todos. $\mathrm{O}$ capital não consegue combater a busca pela emancipação feminina da mesma forma que combatia a classe trabalhadora operária, simplesmente porque tem que preservar a esfera da reprodução social (MÉSZAROS, 2002).

Ainda, a mudança produtiva só será possível dentro do capital, caso haja a mudança na esfera reprodutiva. Ambos os gêneros devem estar conscientes dos seus direitos, e das suas responsabilidades dentro da consciência de classe trabalhadora (MÉSZAROS, 2002). 


\section{REFERÊNCIAS}

ANTUNES, R. Os sentidos do trabalho. São Paulo: Boitempo Editorial, 1999.

BIHR, A. Da grande noite à alternativa. São Paulo: Boitempo, 1998.

CASTRO, M. G. Feminização da pobreza em cenário neoliberal. Brasil 2000. São Paulo: Anitta Garibaldi, 2001.

GOUNET, T. Fordismo e toyotismo na civilização do automóvel. São Paulo: Boitempo, 1999.

HARVEY, D. A condição pós-moderna. Rio de Janeiro: Loyola, 1992.

HIRATA, H.; DOARÉ, H. Os paradoxos da globalização. In: O trabalho das Mulheres.

Cadernos Sempreviva. São Paulo: SOF - Sempreviva Organização Feminista, 1999.

HIRATA, H. Globalização e divisão sexual do trabalho. Cadernos Pagu, Campinas, n. 18/18, p. 139-156, 2002 [2001].

IBGE. Instituto Brasileiro de Geografia e Estatística. Censo brasileiro de 2010. Rio de Janeiro: IBGE, 2012.

MAZZOLENIS, S. Riviera de São Lourenço ontem, hoje e registros. Bertioga: Sistema Integrado de Vendas, 2008.

MENICUCCI, E. A mulher, a sexualidade e o trabalho. São Paulo: Hucitec, 1999.

MÈSZAROS, I. Para além do capital. São Paulo: Boitempo, 2002.

NOGUEIRA, Claudia Mazzei. A feminização no mundo do trabalho: entre a emancipação e a precarização. Campinas, SP: Autores Associados, 2004.

SAFFIOTI, H. A mulher na sociedade de classes. Rio de Janeiro, Vozes, 1976.

SCAVONE, L. Estudos de Gênero: uma sociologia feminista? Revista Estudos Feministas, v. 16, n. 1, jan./abr. 2018.

SCHIENBINGER, L. O feminismo mudou a ciência? Bauru: EDUSC, 2001.

SCOTT, J. W. História das mulheres. In: BURKE, P. (Org.) A escrita da história: novas perspectivas. São Paulo: Unesp, 1992.

SEADE. Fundação Sistema Estadual de Análise de Dados. São Paulo, 2018. 


\section{Como referenciar este artigo}

DARIDO DA CUNHA, Maíra; DIAS RODRIGUES, Guilherme. O mercado de trabalho formal em Bertioga sob a perspectiva de gênero. Rev. Sem Aspas, Araraquara, v. 8, n. 2, p. 180-192, jul./dez. 2019. e-ISSN: 2358-4238. DOI: https://doi.org/10.29373/sas.v8i2.13594

Submetido em: 10/10/20219

Aprovado em: 05/12/2019

Publicado em: 30/12/2019 